\title{
Modeling and Simulation of Impact Failure Characteristic of Polypropylene by Elastoviscoplastic Constitutive Law"
}

\author{
Hiroyuki MAE $^{* *}$, Kikuo KISHIMOTO ${ }^{* * * *}$ \\ "Honda R\&D Co., Ltd. \\ 4630 Shimotakanezawa, Haga-machi, Haga-gun, \\ Tochigi 321-1233, Japan \\ Email: Hiroyuki_Mae@n.t.rd.honda.co.jp \\ ${ }^{* t *}$ Department of Mechanical and Control Engineering, Tokyo Institute of Technology
}

\begin{abstract}
For simulating the final failure of glassy polymers under impact loading, Shizawa's constitutive model was modified by introducing the craze density based softening law in which the phenomenological softening law using the craze density is employed. The material parameter identification procedure in the constitutive law was developed based on the sensitivity analysis. All parameters were identified with the measurement data which were obtained by both the dumbbell-shape tensile test specimen and the notched tensile test specimen. The dart impact test was also conducted. The load displacement curve and damage zone development were compared with those obtained by the finite element analysis using proposed constitutive equations. Both results were in good agreement and the usefulness of the constitutive equations was validated.
\end{abstract}

Key words: Polymer, Impact Failure, Constitutive Equation, Elastoviscoplasticity, Craze density, Softening Law, Finite Element Method

\section{Introduction}

Recently, crash simulations have been used to the vehicle body design in the automotive development. For instance, crash simulations for high strength steel materials, which are the main materials of the automobile main frame structures, currently exhibit high simulation accuracy in axial buckling calculations for structural components, and have reached a level that was sufficient for practical applications ${ }^{(1)}$. On the other hand, the number of polymer components increases especially for the multiple functions of weight reduction and impact energy absorbing such as bumper faces and interior parts ${ }^{(2)(3)}$. In developing such polymer components, it is getting more important to design them by analysis.

In general, polymers show a strong strain-rate dependency and a strong temperature sensitivity compared to metals. In evaluating the energy absorbing performance, inelastic material behavior such as viscoplasticity is the dominant characteristic. For instance, the viscoplastic material constitutive model is used in order to evaluate the impact energy absorbing performance of sheet steels ${ }^{(1)}$.

The dominant inelastic material characteristics of glassy polymers are craze nucleation and growth ${ }^{(4)}$. A vast amount of research has been performed in the past on all aspects of crazing by the experimental approaches ${ }^{(5)-(7)}$. In the numerical simulation point of view, the considerable researches were conducted for developing the constitutive laws so that the post-yield characteristic of glassy polymers could be captured ${ }^{(8-14)}$. Although all the 
constitutive laws ${ }^{(8-10)}$ can capture the post yield characteristic such as craze nucleation, both the craze growth and shear band creation are not considered in one constitutive law. The development of such constitutive models that are able to predict both phenomenon of crazing and shear band creation started off with the work of Shizawa and co-workers ${ }^{(11-14)}$. The non-coaxial constitutive law with craze defects is derived and validated based on both flow theory and thermodynamics ${ }^{(11)(12)}$. Then, they propose the elastoviscoplastic constitutive law based on craze evolution and annihilation ${ }^{(13)(14)}$. Their constitutive law consists of strain-rate hardening law, craze nucleation law and craze evolution law. Strain-rate hardening equation is the exponential hardening law. The craze nucleation law consists of the hydrostatic stress criterion. The craze evolution law is the function of the mean normal plastic strain and the hydrostatic stress. Shizawa constitutive model is validated with the static tensile test result obtained with the dumbbell-shape test specimen of polypropylene and polycarbonate. Their simulated results show the good accuracy but the experimental validations are not conducted in deformation and failure characteristics at the intermediate and high strain rates.

In the practical applications, however, it is getting necessary to use the material constitutive law including the ductile failure model so that the total impact energy absorbing performance can be evaluated for glassy polymer components.

In addition, Shizawa constitutive model has quite a few material parameters, which makes it more difficult to implement the simulation in the industrial applications.

Then, the first objective in this paper is to modify Shizawa constitutive model by introducing the craze density based softening law for simulating the ductile failure of glassy polymers. The second is to show the material parameters identification procedure in the constitutive law with the material parameter sensitivity analysis. Finally, the impact deformation and failure characteristic are simulated and validated with the identified material parameters. First, the phenomenological softening law is proposed with the craze density. Next, the preliminarily sensitivity analysis is conducted so that the efficient parameter identification procedure can be proposed. Then, each parameter is identified with the measurement data which are obtained by both the dumbbell-shape tensile test specimen and the notched tensile test specimen at the intermediate and high strain rates. Finally, the simulated macroscopic load displacement curve and damage zone development are compared and validated with the dart impact test result. The tested material in this study is the elastomer blended polypropylene used in the interior and exterior parts of automobiles. All the simulations are implemented by using a commercial explicit finite element code RADIOSS version 4.4 with user defined material subroutine program.

\section{Material Constitutive Law}

For the numerical simulation, the above mentioned elastoviscoplastic constitutive equation with craze effect is applied to the dumbbell-shape tensile test, notched tensile test and dart impact test.

According to Ref.(13), the proposed elastoviscoplastic constitutive equation with craze effect is shown as Eq. (1);

$$
\stackrel{\nabla}{\mathbf{T}}=\mathbf{C}^{v}: \mathbf{D}-\dot{\bar{\varepsilon}}^{p}(\cos \delta) \mathbf{P}^{\prime}-\dot{\omega} \mathbf{T} /(1-\omega),
$$

where $\mathbf{T}$ is Cauchy stress, $\mathbf{D}$ is deformation rate, $\dot{\bar{\varepsilon}}_{\nabla}^{p}$ is equivalent plastic strain rate, $\omega$ is craze density, $\dot{\omega}$ is craze density rate and ( ) is Jaumann rate. $\mathbf{C}^{v}, \mathbf{P}^{\prime}$ and $\cos \delta$ are defined in the following equations;

$$
\begin{gathered}
\mathbf{C}^{v} \equiv H_{\omega}(1-\omega) /\left(H_{\omega}+3 \mu\right)\left[\mathbf{C}^{\mathrm{e}}+3 \mu / H \times\left\{(3 \lambda+2 \mu) / 3 \mathbf{I} \otimes \mathbf{I}+3 \mu \mathbf{T}^{\prime} \otimes \mathbf{T}^{\prime} / \bar{\sigma}^{2}\right\}\right], \\
\mathbf{P}^{\prime} \equiv \mathbf{C}^{v}: \mathbf{m}^{\prime}=3 \mu(1-\omega) \mathbf{T}^{\prime} / \bar{\sigma}, \quad \mathbf{m}^{\prime} \equiv 3 / 2 \mathbf{T}^{\prime} / \bar{\sigma}, \\
H_{\omega} \equiv 1 /(1-\omega) \overline{\dot{\sigma}} /\left(\dot{\bar{\varepsilon}}{ }^{p} k\right), \quad \overline{\dot{\sigma}} \equiv\left(3 \stackrel{\nabla}{\mathbf{T}^{\prime}} \cdot \stackrel{\nabla}{\mathbf{T}^{\prime} / 2}\right)^{1 / 2},
\end{gathered}
$$




$$
\cos \delta=\left(1-\sin ^{2} \delta\right)^{1 / 2}, \quad \sin \delta=k(m) \sin \alpha,
$$

where $\mathbf{m}^{\prime}$ is stress direction tensor, $m$ is the strain rate sensitivity parameter and $\cos \alpha$ is defined as

$$
\cos \alpha \equiv \mathbf{T}^{\prime} \cdot \stackrel{\nabla}{\mathbf{T}^{\prime}}\left(\mathbf{T}^{\prime} \cdot \mathbf{T}^{\prime}\right)^{-1 / 2}\left(\stackrel{\nabla}{\mathbf{T}^{\prime}} \cdot \stackrel{\nabla}{\mathbf{T}}^{\prime}\right)^{-1 / 2}
$$

The craze evolution equation is proposed in the following equation [14];

$$
\dot{\omega}=A(1-\omega)\left\langle\dot{\varepsilon}_{m}^{p}\right\rangle+B \cdot D_{1}^{\dot{\bar{\varepsilon}}^{p}} \cdot 0.5\left[1+\tanh \left\{-D_{2}\left(\bar{\varepsilon}^{p}-\varepsilon_{c}\right)\right\}\right] \cdot \dot{\bar{\varepsilon}}^{p},
$$

where $A, B, D_{1}$ and $D_{2}$ are material constants. $\dot{\varepsilon}_{m}^{p}$ is the mean normal plastic strain rate defined as

$$
\dot{\varepsilon}_{m}^{p}=\left\{\left(q_{1} \omega\right) \cosh \left(\left(q_{2} \omega+q_{3}\right) \sigma_{m} / \sigma_{y}\right)\right\}
$$

where $\sigma_{m}$ is the hydrostatic stress, $\sigma_{y}$ is the yield stress, $q_{1}-q_{3}$ are material constants. The first part of Eq. (7) means craze evolution and the second one means the craze creation and growth. $\varepsilon_{c}$ is the strain at which the craze stops growing. The craze generation is based on the hydrostatic stress criterion as Eq. (9);

$$
\sigma_{b} \geq A_{1}+\left(B_{1} / 3 \sigma_{m}\right) \quad \sigma_{b}=\sigma_{1}-v \sigma_{2}-v \sigma_{3},
$$

in which $\sigma_{b}$ is stress needed for fibril orientation, $\sigma_{m}$ is hydrostatic stress, $\sigma_{1}-\sigma_{3}$ are principal stresses, $A_{l}$ and $B_{l}$ are material constants.

With strain rate dependent coefficient $\mathrm{m}$, the strain hardening equation is modeled in the following equations;

$$
\begin{gathered}
\dot{\bar{\varepsilon}}^{p}=\varepsilon_{r} \mid \bar{\sigma} / g\left(\bar{\varepsilon}^{p}\right)^{1 / m}, \\
g\left(\bar{\varepsilon}^{p}\right)=\sigma_{r}\left\{\tanh \left(k_{1} \bar{\varepsilon}^{p}\right)+k_{2}+H_{e}\left(\bar{\varepsilon}^{p}-\varepsilon_{r}\right) k_{3}\left(\exp \bar{\varepsilon}^{p}-\exp \varepsilon_{r}\right)\right\},
\end{gathered}
$$

where $g\left(\bar{\varepsilon}^{p}\right)$ is the flow stress modeled for polypropylene ${ }^{(14)}, \dot{\varepsilon}_{r}$ is the reference strain rate, $\sigma_{r}$ is the reference stress, $\varepsilon_{r}$ is the reference strain at which the second hardening begins. $k_{1}-k_{3}$ are material constants. $H e(x)$ is the following step function.

$$
H_{e}(x)=1 \quad(\text { at } \mathrm{x}>0), \quad 0(\text { at } \mathrm{x}<0) .
$$

In this study, the tensile softening law is proposed in order to simulate the ductile failure due to craze evolution. Ductile failure due to craze occurs when the fibril which consists of hundreds or thousands of molecular chains breaks continuously to some extent. The load displacement curve of fibril break is simulated with coarse molecular dynamics model $^{(15)}$. The phenomenological softening law based on craze density is defined as Eq. (13);

$$
f(\omega)=1-\tanh \left\{\left(\omega-w_{2}\right) w_{3}\right\},
$$

where $w_{2}$ is the craze density at which the softening effect starts being activated and $w_{3}$ is the softening parameter. This softening law is multiplied by the flow stress Eq.(11) during each calculation step.

All FEM simulations are performed by the commercial explicit finite element code RADIOSS version 4.4. Figure 1 shows the finite element mesh used for the dart impact test. Similar to the experiment, the impacting dart is controlled by constant velocities in FE analyses. The axial load is obtained by FE analyses. In addition, the craze density distribution is obtained in the dart impact test. In this simulation, the three-dimensional solid element is used as shown in Fig. 1.

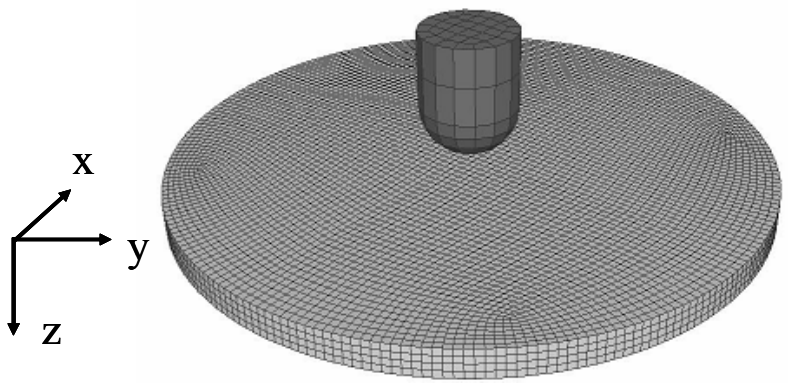

Fig. 1 FE Model of Dart Impact Test 


\section{Experimental Procedure}

\subsection{Tensile Test Specimens}

A thermoplastic semi-crystalline material, elastomer modified polypropylene, is selected for this study from among polymers widely used in the interior and exterior of automobiles. JISK 713 No. 2 dumbbell shape (parallel portion width $6 \mathrm{~mm}$ ) test specimens in JIS (Japanese Industrial Standards) are used from the static tensile to the medium-speed tensile (up to nominal strain rate of $10^{1} \mathrm{sec}^{-1}$ ) range for measuring the strain rate dependent stress strain relationship, and the notch tensile test specimens designed exclusively for the parameter identification are used only at the nominal strain rate of $10^{1}\left(\mathrm{sec}^{-1}\right)$. In the practical application, the fracture is often observed at the location where the ribs are connected with the flat surface of polymer parts. That is, the location where the high stress tri-axiality is observed leads to the fracture initiation. Then, the notched tensile specimen is used so that the parameters should be identified for a high stress tri-axial distribution. Figures 2 and 3 show the respective test specimen shapes. The thickness of test specimens is $3.6 \mathrm{~mm}$.

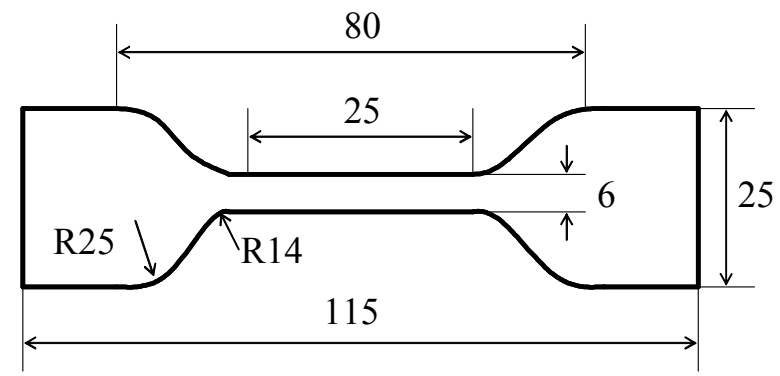

Fig. 2 Schematic Illustration of Smooth Test Specimen

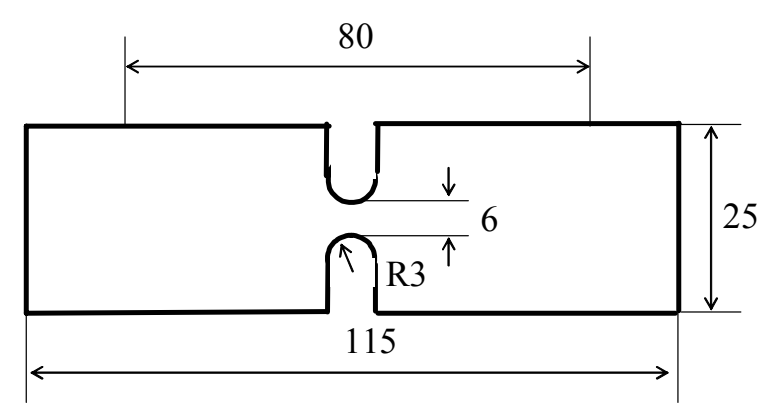

Fig. 3 Schematic Illustration of Notched Test Specimen

\subsection{Test Apparatus and Method}

This study uses a Type AG screw-driven system (AGS 1000G: maximum tensile speed $1.7 \times 10^{-2} \mathrm{~m} / \mathrm{s}$ ) to obtain mechanical characteristics in the static to quasi-static range (nominal strain rate $10^{-4} \mathrm{sec}^{-1}$ to $10^{-1} \mathrm{sec}^{-1}$ ), and Type A (EHF U2H-20L: maximum tensile speed $1.5 \times 10^{1} \mathrm{~m} / \mathrm{s}$ ) servo-hydraulic high-speed impact test apparatuses to obtain mechanical characteristics during medium- to high-speed deformation. The strain rate is the nominal value calculated by the initial clamping distance of the test specimen which is 80 $\mathrm{mm}$. Figure 4 shows the principle of operation for the impact test apparatus. Two types of testing apparatuses are employed for the tensile test according to the nominal strain rate as shown in Table 1. As reported in Ref.(16), load displacement curves measured with JIS2 test specimens at the nominal strain rate of $10^{-1}(1 / \mathrm{sec})$ by using Type AG and Type A were well coincide with each other. The experimental errors due to the difference in testing apparatuses on the load displacement measurement could be negligible. Note that the in-plane deformation of the test specimen is recorded during the tensile test in order to 
measure the longitudinal strain and the lateral strain. This is done using a home video camera (SONY) in the low-speed tensile range, and a high-speed video camera (NAC) capable of recording 20000 frames/sec in the impact tensile test.

Table 1 Test Conditions

\begin{tabular}{|c|c|c|}
\hline Crosshead Velocity & Nominal Strain Rate & Testing Apparatus \\
\hline \hline $8 \times 10^{-6} \mathrm{~m} / \mathrm{s}$ & $10^{-4}$ & \multirow{2}{*}{$\begin{array}{c}\text { Type AG: AGS-1000G } \\
\text { JIS2 Test Specimen }\end{array}$} \\
\hline $8 \times 10^{-5} \mathrm{~m} / \mathrm{s}$ & $10^{-3}$ & \\
\hline $8 \times 10^{-4} \mathrm{~m} / \mathrm{s}$ & $10^{-2}$ & \\
\hline $8 \times 10^{-3} \mathrm{~m} / \mathrm{s}$ & $10^{-1}$ & Type A: EHF-U2H-20L \\
\hline $8 \times 10^{-3} \mathrm{~m} / \mathrm{s}$ & $10^{-1}$ & JIS2 Test Specimen \\
Notched Test Specimen
\end{tabular}

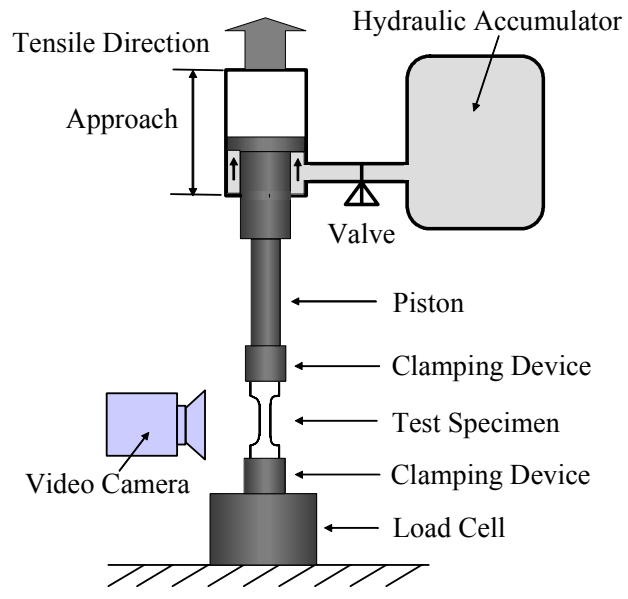

Fig. 4 Schematic Illustration of Tensile Testing Apparatus

With the same test apparatus as the middle-speed tensile test, the dart impact test is conducted as shown in Fig. 5. The impact velocities are 0.1 and $1.0(\mathrm{~m} / \mathrm{sec})$. The diameter of the dart is $12.7 \mathrm{~mm}$. The test specimen is a square plate of dimensions $110 \times 110 \times 3.4$ $\mathrm{mm}$ and is clamped by the square plate which has the $76 \mathrm{~mm}$ diameter hole. The high-speed video camera (NAC) is located just underneath the test specimen so that the dame zone development can be recorded during dart penetration process.

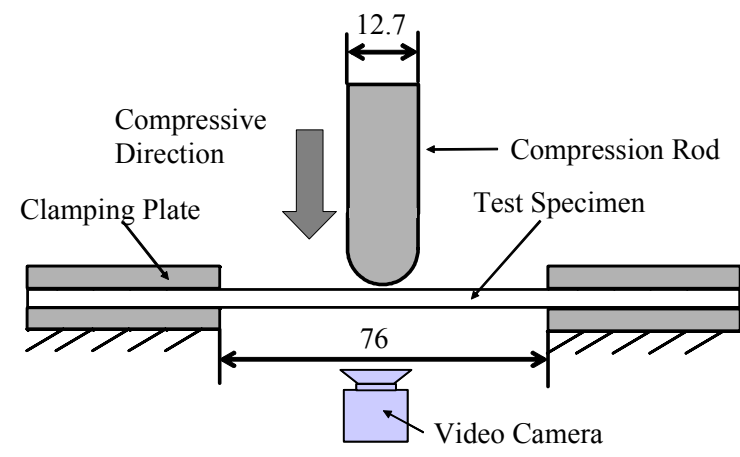

Fig. 5 Schematic Illustration of Dart Impact Test 


\section{Results and Discussion}

\subsection{Parameter Sensitivity Analysis}

The number of material parameters is quite a few so the material identification procedure should be specified. At first, the parameter sensitivity is analyzed. Then the material parameter identification procedure is determined with the result of sensitivity analysis. The objective parameter is the function of all the parameters in the following equation;

$$
y=\text { const }+s_{1} x_{1}+s_{2} x_{2}+s_{3} x_{3}+s_{4} x_{4}+s_{5} x_{1} x_{2}+s_{6} x_{1} x_{3}+\cdots,
$$

where $y$ is the objective parameter, $x_{i}$ is each parameter and $s_{i}$ is scaled coefficients. Then each scaled coefficient can be normalized as following formula;

$$
N_{x}=100 \times S_{x} /\left(\sum_{j}\left|S_{x j}\right|\right),
$$

where $N_{x}$ is the normalized of scaled coefficient.

The parameter sensitivities are analyzed in the JIS2 dumbbell-shape tensile test simulation and the notched tensile test simulation. Based on the results, the material identification procedure is proposed in this study.

\subsection{Result of Parameter Sensitivity Analysis}

In the case of dumbbell-shape tensile test at the nominal strain rate of $10^{1}(1 / \mathrm{sec})$, the pareto plots for the loads at each tensile displacement are shown in Figures 6(a), 6(b), 6(c) and $6(\mathrm{~d})$. The black color of the bar graph means the positive effect and the shaded one means the negative effect.
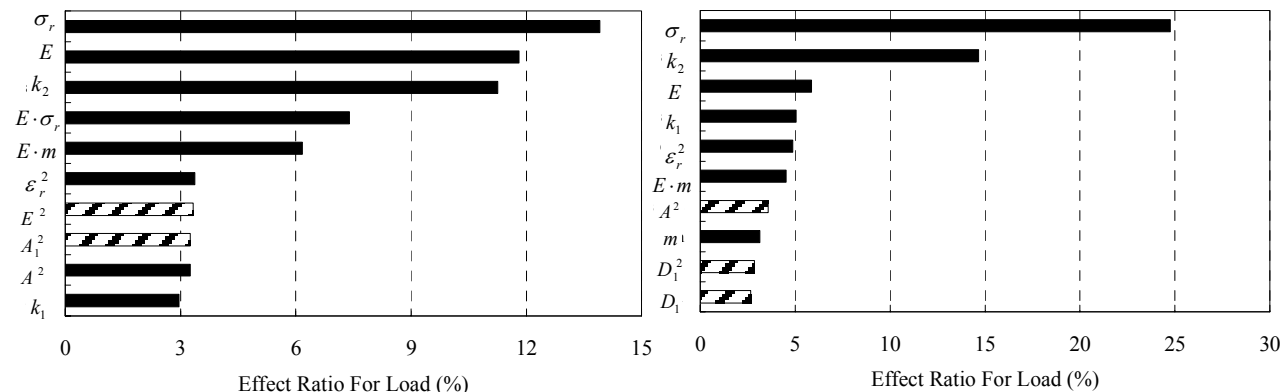

Fig. 6(a) Pareto Plot for Load at $1 \mathrm{~mm}$

Fig. 6(b) Pareto Plot for Load at $2 \mathrm{~mm}$

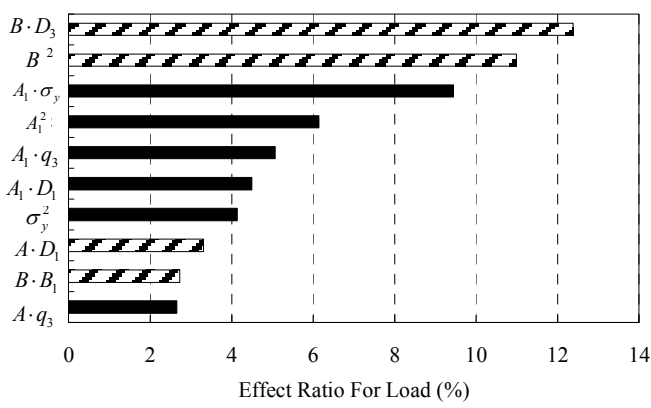

Fig. 6(c) Pareto Plot for Load at 5mm

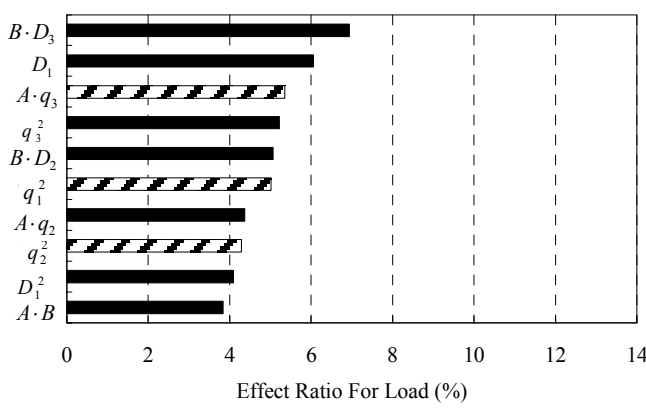

Fig. 6(d) Pareto Plot for Load at 10mm

In Figs. 6(a) and (b), most of the dominant material parameters compose the strain hardening equation in Eqs. (9) and (10). This is because the displacements of 1 and $2 \mathrm{~mm}$ correspond to the elastic deformation and the first yielding in the case of JIS2 dumbbell-shape tensile test specimen. The comparison between Figures 6(c) and 6(d) shows that the parameter sensitivity at $5 \mathrm{~mm}$ is much clearer than that of $10 \mathrm{~mm}$. This result 
suggests that the dominant parameters at $5 \mathrm{~mm}$ should be identified in this particular case. In the case of the notched tensile test simulation at the nominal strain rate of $10^{1}(1 / \mathrm{sec})$, the pareto plots for the loads at each tensile displacement are shown in Figures 7(a), 7(b) and $7(\mathrm{c})$.

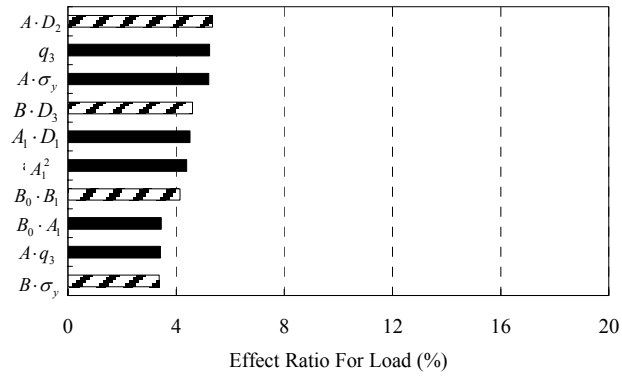

Fig. 7(a) Pareto Plot for Load at $1 \mathrm{~mm}$

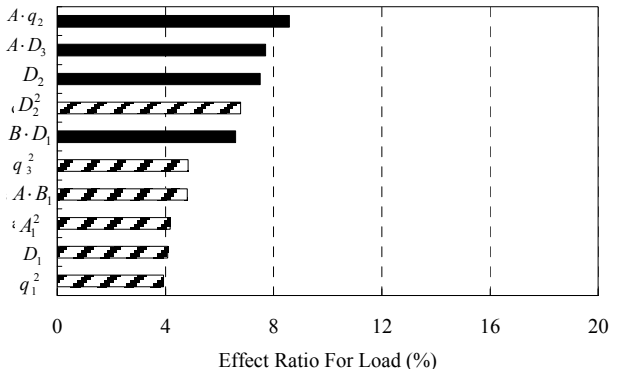

Fig. 7(b) Pareto Plot for Load at $2 \mathrm{~mm}$

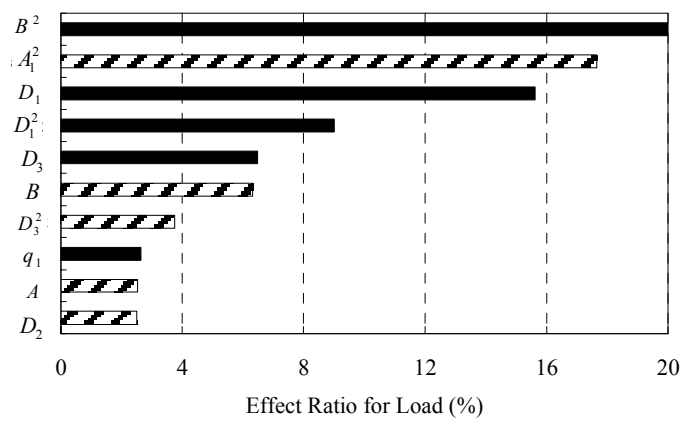

Fig. 7(c) Pareto Plot for Load at 3mm

Most of the dominant parameters shown in Fig. 7(c) are the material parameters for craze nucleation and growth. This is because the high stress triaxiality occurs in the notched tensile specimen. This result suggests that most of the material parameters for craze nucleation and growth should be identified at the large displacement of the notched tensile test simulation. Based on the results of the material parameter sensitivity analyses, the parameter identification procedure is proposed as shown in Figure 8. The identified material parameters are shown in Table 2. These material parameters would not be the best picks for any loading conditions in the practical applications. In addition, the material parameters do not have uniqueness. However, it is thought that they are optimized for the specific loading conditions in this study.

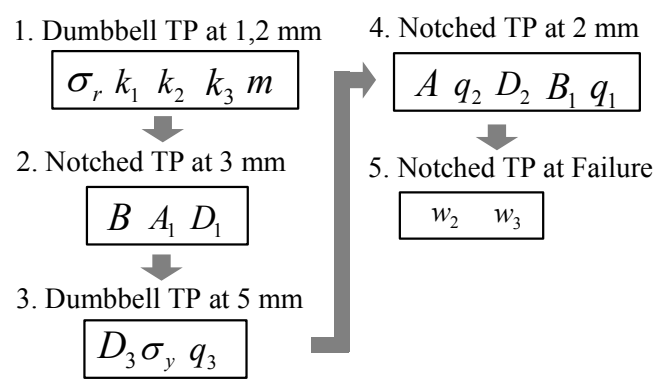

Fig. 8 Material Parameter Identification Procedure 
Table 2 Material Parameters

\begin{tabular}{cccc}
\hline$A$ & 0.383 & $\sigma r$ & 10.055 \\
$B$ & 1.226 & $\sigma y$ & 17.432 \\
$A_{1}$ & 1.982 & $k 1$ & 44.795 \\
$B_{1}$ & 417.665 & $k 2$ & 0.863 \\
$D_{1}$ & 0.999 & $k 3$ & 1.243 \\
$D_{2}$ & 100.541 & $q 1$ & 0.0001177 \\
$\varepsilon_{c}$ & 1.087 & $q^{2}$ & 12.44 \\
$m$ & 0.069 & $q^{3}$ & 2.908 \\
$\dot{\varepsilon} r$ & 1 & $w_{2}$ & 0.22425 \\
$\varepsilon_{r}$ & 0.0001 & $w 3$ & 4.0968 \\
\hline
\end{tabular}

\subsection{Experimental Results}

Stress vs. strain relationships at various nominal strain rates are shown in Figure 9. The incompressibility of the materials is assumed for large deformations in order to obtain the true stress by simple calculation in this study. The ratio of the longitudinal strain and the lateral strain under large deformations was estimated as about -0.46 . Thus, it is presumed that the estimated true stress is in the error range of several percentages. It is clearly observed that the tested material has the strong strain rate dependency.

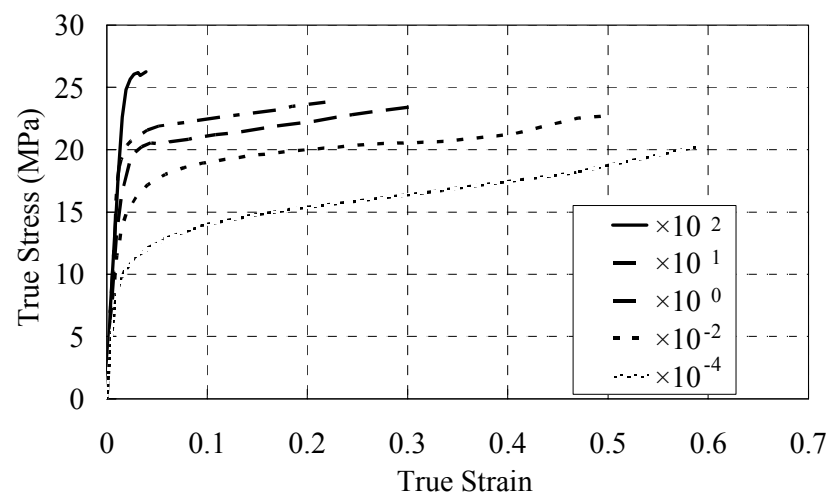

Fig. 9 True Stress Strain Curves at Various Strain Rates

Figure 10 shows the load-displacement histories at the impact velocities of 0.1 and 1.0 $(\mathrm{m} / \mathrm{sec})$. As clearly shown in this figure, the load level gets higher at the higher impact velocity.

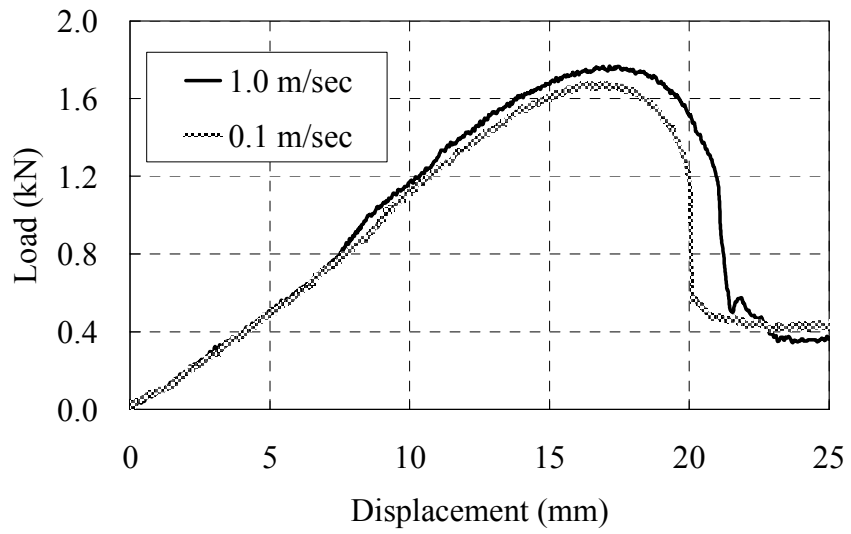

Fig. 10 Load Displacement Histories at Dart Impact Test 


\subsection{Comparison between Experimental and Simulated Results: Tensile Test}

Figure 11 shows the experimental and numerical load displacement histories of JIS2 tensile test at the nominal strain rates of $10^{0}$ and $10^{1}(1 / \mathrm{sec})$. The simulated load displacement history shows the same trend as what the experimental results show.

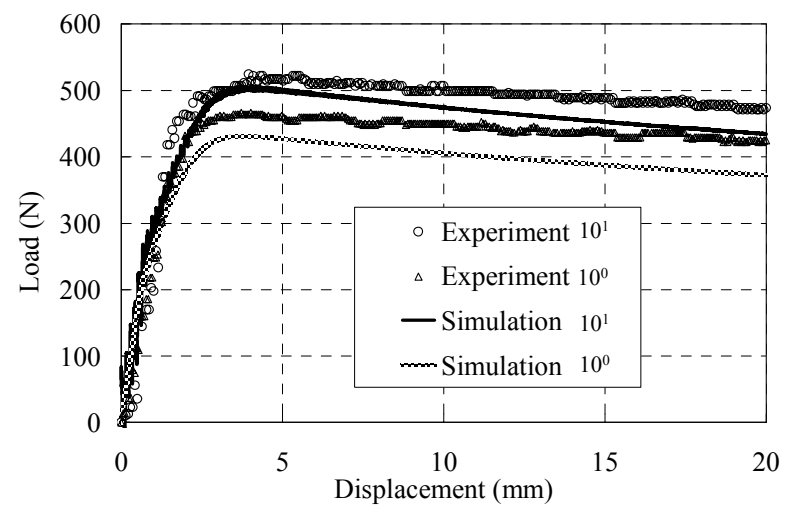

Fig. 11 Load Displacement Curves of Smooth TP

Figure 12 shows the load displacement curves of the notched tensile test at the tensile velocity of $0.8(\mathrm{~m} / \mathrm{sec})$. In comparison with the smooth tensile test specimen, the notched tensile test result shows the strong softening effect by which the load decreases gradually. The simulated load displacement curve without proposed softening law shows a good agreement with the experimental result by the displacement of $2 \mathrm{~mm}$ but it can not show the final failure characteristic. However, the simulated result with the softening law shows the load decrease caused by final failure. It is suggested that the proposed softening law can handle the final failure characteristic which consists of fibril breaks.

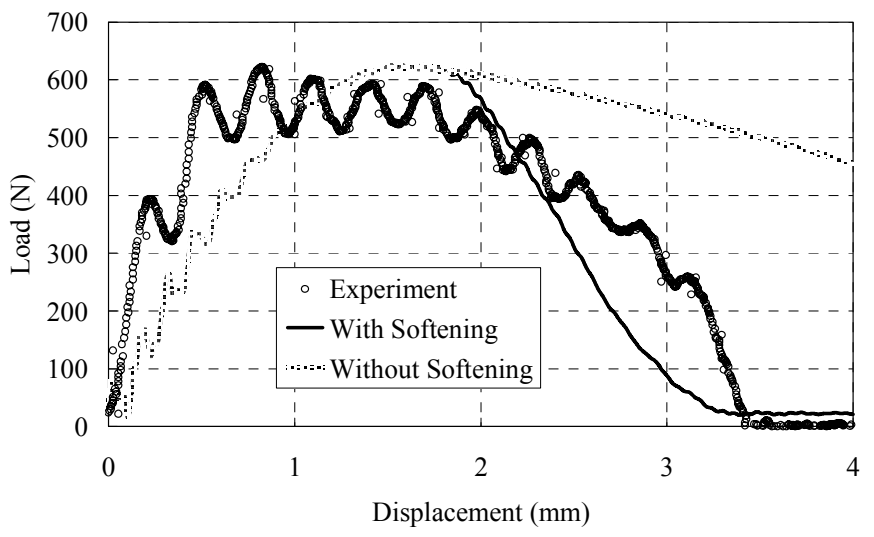

Fig. 12 Load Displacement Curves of Notched TP

\subsection{Comparison between Experimental and Simulated Results: Dart Impact Test}

Figures 13 and 14 show the experimental and simulated load displacement histories of dart impact test and simulations at the impact velocities of 0.1 and $1.0(\mathrm{~m} / \mathrm{sec})$. In the case without the proposed softening law, the simulated load indicates the higher value that the experimental one. However, the simulated load with the proposed softening law show the good agreement with the experimental one. This is because the final failure such as fibril breaks occurs continuously during the dart penetration process. Figure 15 shows the lower surface deformation of the test specimen during the dart penetration at the impact velocity of $1.0(\mathrm{~m} / \mathrm{sec})$. When the dart displacement $\mathrm{z}$ is $5.0 \mathrm{~mm}$, the craze begins to be generated and then the craze density grows along the contact edge between the dart and the test specimen. The final failure initiates at the dart displacement of $13 \mathrm{~mm}$ and then the final 
failure region propagates along the contact edge as shown in Fig. 15(c), (d). Figure 16 shows the simulated craze density distributions of test specimen during the dart impact at the impact velocity of $1.0(\mathrm{~m} / \mathrm{sec})$. Compared to Figure 16 , the craze generation and growth are simulated quite similarly.

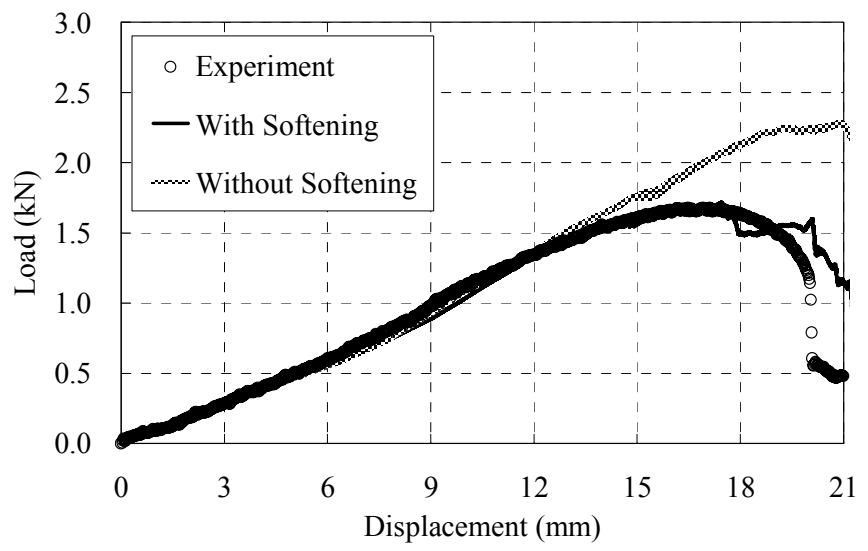

Fig. 13 Load Displacement Curves of Dart Impact Test and Simulation at $0.1 \mathrm{~m} / \mathrm{sec}$

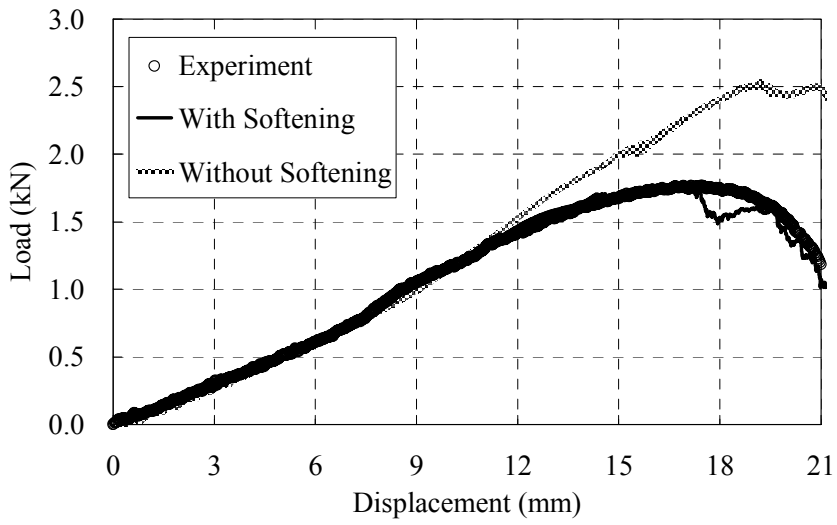

Fig. 14 Load Displacement Curves of Dart Impact Test and Simulation at $1.0 \mathrm{~m} / \mathrm{sec}$

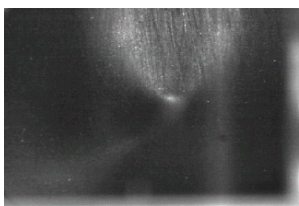

(a) $\mathrm{z}=5 \mathrm{~mm}$

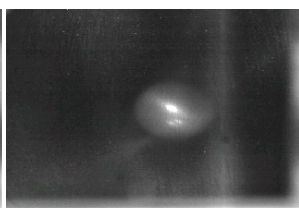

(b) $\mathrm{z}=10 \mathrm{~mm}$

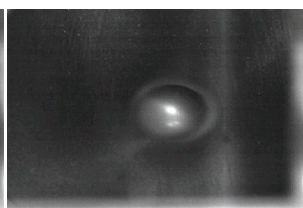

(c) $\mathrm{z}=13 \mathrm{~mm}$

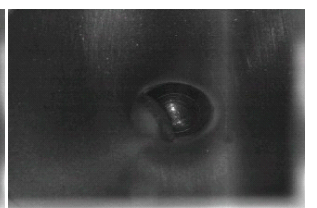

(d) $\mathrm{z}=15 \mathrm{~mm}$

Fig. 15 Photographs of Lower Surface of Dart Impact Test

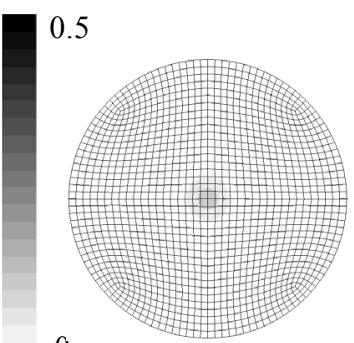

(a) $\mathrm{z}=5 \mathrm{~mm}$

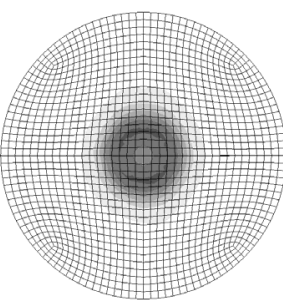

(b) $\mathrm{z}=10 \mathrm{~mm}$

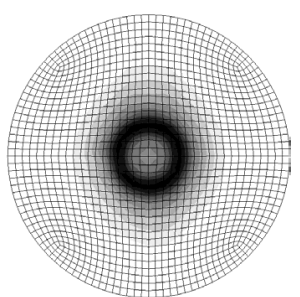

(c) $\mathrm{z}=13 \mathrm{~mm}$

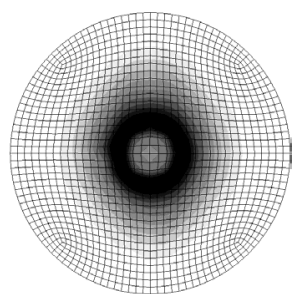

(d) $\mathrm{z}=15 \mathrm{~mm}$

Fig. 16 Simulated Craze Density Distribution of Lower Surface of Dart Impact Test 


\section{Conclusion}

The elastoviscoplastic constitutive law proposed by Shizawa et al. was modified to simulate the final failure of polymer materials under impact loading by introducing the craze density based softening law. A procedure for the material parameter identification in the modified constitutive law was developed based on the parameter sensitivity analyses. In this procedure, all material parameters can be identified by using the load displacement histories of a smooth specimen together with a notched specimen under uniaxial tensile loading. Finite element analyses on the dart impact test were conducted and compared with the experimental results. Numerical results of load displacement histories obtained by the modified constitutive law were in good agreement with the experimental results up to the final failure. Development of damage zone predicted by FE analysis was also in good agreement with that in the experiment. It is concluded that consideration of craze density softening law is recommended to simulate the failure process of the component made by polymeric materials under impact loading.

\section{References}

(1) Cady, M., et al., Dynamic Material Testing and Constitutive Modeling of Structure Sheet Steel for Automotive Applications, Final Progress Report, Los Alamos National Laboratory (1996).

(2) Fujii, M., et al., Study of Impact Analysis for Plastic Parts with Rib Structure Part I, JSAE Annual Congress Proceedings (2000).

(3) Keuerleber, M., Eyerer, P., High-Speed Tensile Testing of Polymers and its Application to an Instrument Panel, Roell Amsler Symposium (2002).

(4) Brostow, W., Corneliussen, R., Failure of plastics, (1986), Hanser Publishers.

(5) Kambour, R.P., J. Polym. Sci., Macromolecular Reviews, 7 (1973), pp.1-154.

(6) Ishikawa, M., Narisawa, I., Ogawa, H., J. Polym. Sci., Polymer Physics Ed. 15, 10 (1977), pp.1794-1804.

(7) Ishikawa, M., Ogawa, H., Narisawa, I., J. Macromol. Sci., Part B: Phys, B19, 3 (1981), pp. 421-443.

(8) Boyce, M.C., Park, M.C., Argon, A.S., Mech. Mater., 7, 1 (1988), pp.15-33.

(9) Arruda, E.M., Boyce, M.C., Int. J. Plast., 9, 6 (1993), pp.697-720.

(10) Wu, P.D., Van der Giessen, E., J. Mech. Phys. Solids, 41, 3 (1993), pp.427-456.

(11) Murakami, D., Kobayashi, S., Torigaki, T., Shizawa, K., A Thermomechanical Modeling and Simulation of Viscoplastic Large Deformation Behavior for Polymeric Materials: 1st Report, Transactions of the Japan Society of Mechanical Engineers, Series A, 68 , No. 668 (2002), pp. 674-681.

(12) Murakami, D., Kobayashi, S.,Torigaki, T., Shizawa, K. A Thermomechanical Modeling and Simulation of Viscoplastic Large Deformation Behavior for Polymeric Materials: 2nd Report, Transactions of the Japan Society of Mechanical Engineers, Series A, 68 , No. 668 (2002), pp. 682-689.

(13) Kobayashi, S., Tomii, D., Shizawa, K., A Modelling and Simulation on Failure Prediction of Ductile Polymer Based on Craze Evolution and Annihilation, Transactions of the Japan Society of Mechanical Engineers, Series A, 70 , No. 694 (2004), pp. 810-817.

(14) Nakagaki, N., Ebihara, M., Kobayashi, S., Shizawa, K., A Modelling and Simulation of Failure Prediction of Glassy Polymer Based on Growth Cessation of Craze with Softening-Hardening Law, Proceedings of the 17th Computational Mechanics Conference (2004), pp. 129-130.

(15) Mae, H., Analysis on Mechanical Behavior of Polypropylene by Coarse-Grained Molecular Dynamics Model, Proceedings of the 13th International Conference on Deformation, Yield and Fracture of Polymers, 134, (2006), pp. 497-500.

(16) Mae, H., et al., Non-Linear Strain Rate-Dependent Behavior of Polymer at Room 
Temperature: Experimental Findings and Calculation Results, Honda R\&D Technical Review, 16, No.1 (2004), pp. 165-172. 